\title{
Distribution and Bionomic of Sand Flies in Five Ecologically Different Cutaneous Leishmaniasis Foci in Morocco
}

\author{
Chafika Faraj, ${ }^{1}$ El Bachir Adlaoui,, Souad Ouahabi, ${ }^{1}$ Mohamed El Kohli, \\ Mohamed El Rhazi, ${ }^{1}$ Lhoussine Lakraa, ${ }^{1}$ and Btissam Ameur ${ }^{2}$ \\ ${ }^{1}$ Laboratoire d'Entomologie Médicale, Institut National d'Hygiène, 27 Avenue Ibn Batouta, Agdal, Rabat 10090, Morocco \\ ${ }^{2}$ Service de Lutte Antivectorielle, Direction de l'Epidémiologie et de Lutte contre les Maladies, Agdal, Rabat 10080, Morocco
}

Correspondence should be addressed to Chafika Faraj; chafikaf@gmail.com

Received 30 April 2012; Accepted 16 July 2012

Academic Editors: J. M. Ramon and C. Szmaragd

Copyright (C) 2013 Chafika Faraj et al. This is an open access article distributed under the Creative Commons Attribution License, which permits unrestricted use, distribution, and reproduction in any medium, provided the original work is properly cited.

Cutaneous and visceral leishmaniases are endemic in Morocco. Their geographical distribution is well known. It has been related to bioclimatic factors. However, in 2008, two new cutaneous leishmaniasis foci appeared out of the known risk areas. Hence, we have undertaken this entomological survey in five foci situated in different bioclimatic areas to better understand the distribution and the epidemiology of this disease. Results of this study, undertaken during 2011, showed the predominance of Phlebotomus sergenti (55.8\%) followed by Ph. perniciosus (12.9\%), Ph. longicuspis (12.3\%), and Ph. papatasi (12.0\%). Ph. sergenti was active during 6 months in subhumid area and 8 months in arid, semiarid, and Saharan areas. Compared to previous studies, our results show a rise in $P h$. sergenti abundance and an extension of its activity period. These results could explain the increase in anthroponotic cutaneous leishmaniasis incidence in Morocco and its extension to new nonendemic regions. Ph. perniciosus and Ph. longicuspis have also displayed a large distribution and a long activity period indicating a high potential risk of Leishmania infantum transmission in the studied areas.

\section{Background}

Leishmaniases are endemic in Morocco with two described forms; visceral (VL) and cutaneous (CL). Two types of $\mathrm{CL}$ are observed: anthroponotic (ACL) and zoonotic (ZCL) leishmaniases. Mucocutaneous leishmaniasis was described in Morocco but remains rare [1].

The geographical distribution of different leishmaniasis forms in Morocco has been clearly defined [2, 3]. It was related to bioclimatic areas described in Morocco. According to Rioux et al. [4], bioclimate affects the vector's distribution and density and hence disease prevalence. VL due to Leishmania infantum is sporadic but extending on large parts of Morocco in all bioclimatic areas because of the large distribution of its sandflies vectors; Phlebotomus longicuspis, $P h$. Perniciosus, and Ph. ariasi. The ZCL caused by L. major is endemic especially in the southern slopes of the Atlas Mountains where its unique vector, $P h$. papatasi and its reservoir host, Meriones shawi, are prevalent. While the ACL due to $L$. tropica is endemic in arid and semiarid regions in the center and mainly in northwestern slopes of the Atlas Mountains where its proven vector $P h$. sergenti is dominant.

Over the last years, leishmaniases have emerged or spread in many countries of Europe especially in the Mediterranean region. Most of declared outbreaks have been linked to global and local changes resulting of climatic changes or growth in human populations and their activities [5]. In Morocco, leishmaniasis distribution has also gradually spread since 2001. In 2008, two new ACL foci appeared out of the known risk areas, previously defined by Public Health Services. The first one in the northeast of the country on the eastern hillside of the Middle Atlas mountains in a subhumid region (province of Boulmane) and the second in the southeast of the country on the east slopes of the High Atlas mountains in a Saharan region (province of Tinghir). Knowledge of vectors' population's distribution and dynamics is important in predicting the spatial and temporal variations in the risk of disease. However, information on dynamics of Leishmania vectors is limited in Morocco. Few localized and short-term studies are published [6-8]. Hence, to better understand 

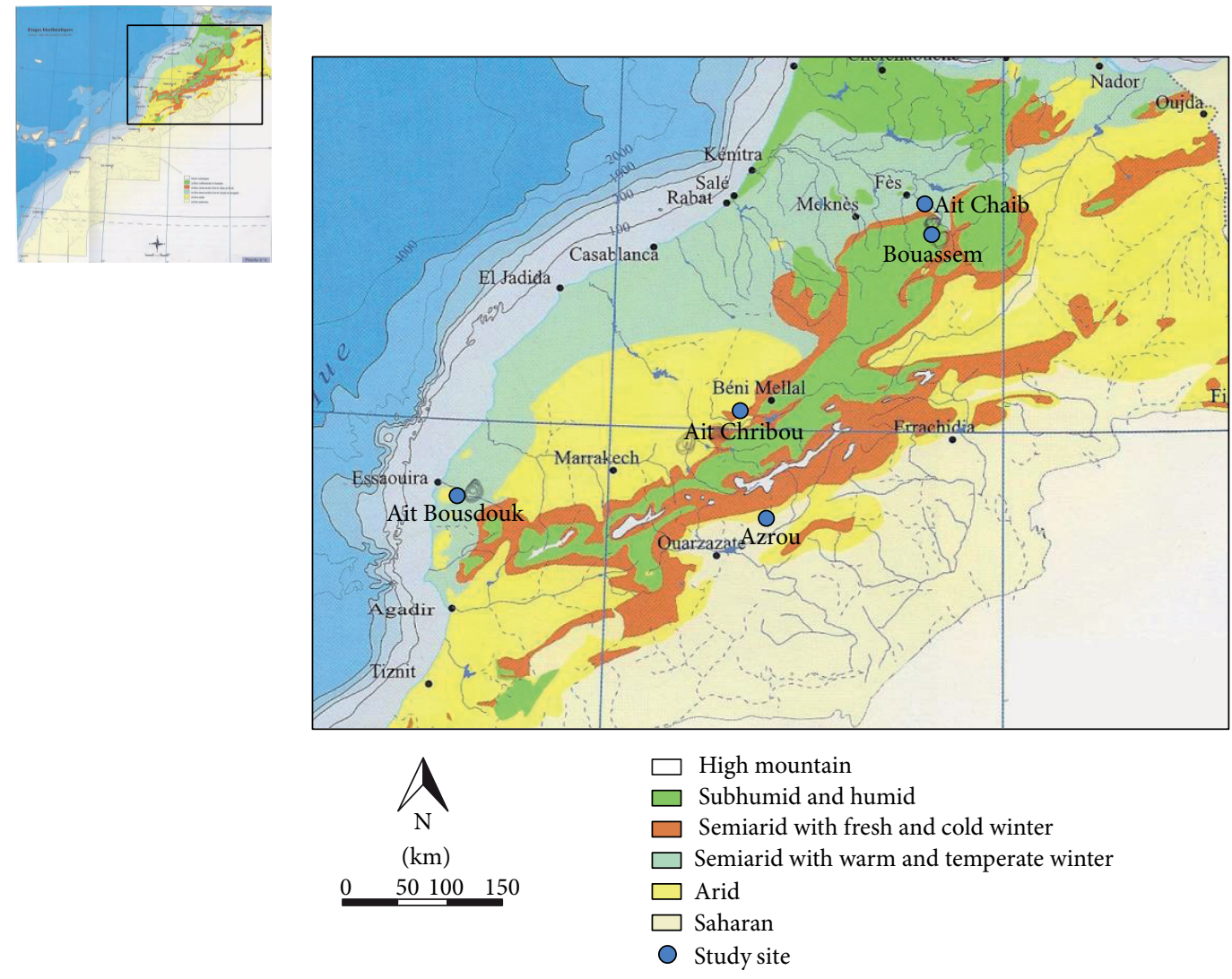

FIGURE 1: Map showing the five study site locations.

epidemiology and distribution of leishmaniasis in Morocco, we have undertaken this study in five different stations that represent the main biotopes in the country. Results of this study will help to establish effective and appropriate vector control measures. This study aims also to update entomological data by providing information on richness, abundance, seasonal trend, and spatial distribution of sand flies species.

\section{Material and Methods}

2.1. Study Areas. Morocco is approximately $710,850 \mathrm{sq} . \mathrm{km}$. It is extended on five large geographical units: (1) the Rif Mountain extending in the north of the country; (2) the Atlas Mountains corresponding to central Morocco. They include the Middle, the High, and the Anti-Atlas Mountains; (3) the maritime plains located between the Atlantic Ocean and the western sides of the Atlas Mountains; (4) the pre-Saharan region at the south and the south east of the Atlas Mountains; (5) the Sahara extending on the south part of the country. The large latitudinal extension of Morocco, the importance of its maritime facades and its relief involve a large geographical variation in its climate. So, the annual means of precipitation vary from less than $25 \mathrm{~mm}$ in Sahara to about $2000 \mathrm{~mm}$ in the Rif. The analysis of the climatic map [9] showed five ecological zones, the Saharan bioclimate in the south and east gradually turning to arid, semiarid, subhumid, and humid in high altitudes of Atlas and Rif mountains.

This study was carried out in five leishmaniasis areas located at different altitudes and in different ecological niches (Figure 1).

2.1.1. Ait Chribou Locality. $\left(32^{\circ} 11^{\prime} \mathrm{N}, 06^{\circ} 20^{\prime} \mathrm{W}\right)$ : located on the north of High Atlas chain at $1200 \mathrm{~m}$ above sea level (asl) in a semiarid area. Rainfall is approximately $600 \mathrm{~mm}$ per year. Ait Chribou is belonging to Azilal province, an endemic area of ACL where the first case was reported by Marty et al. [10]. Apart from agriculture, livestock farming is the major source of income in the area.

2.1.2. Ait Bousdouk Locality. $\left(31^{\circ} 31^{\prime} \mathrm{N}, 09^{\circ} 26^{\prime} \mathrm{W}\right)$ : a coastal locality, not far away from the Atlantic Ocean, with an altitude of about $250 \mathrm{~m}$. This station is characterized by an arid climate. The total annual rainfall ranges between 200 and $400 \mathrm{~mm}$. This locality belongs to Essaouira province, an endemic focus of L. tropica [11].

2.1.3. Bouassem Locality. $\left(33^{\circ} 31^{\prime} \mathrm{N}, 04^{\circ} 33^{\prime} \mathrm{W}\right)$ : situated in the northeast of the Middle Atlas Mountains at a height of about $1100 \mathrm{~m}$. Bouassem is characterized by a subhumid bioclimate with moderate winters. This site receives about 
700-800 mm precipitations from October to May. This locality is from Boulmane province, an emerging L. tropica focus where the first human cases were reported in 2008. The population is mainly agricultural.

2.1.4. Aichoune Locality. $\left(33^{\circ} 39^{\prime} \mathrm{N}, 04^{\circ} 38^{\prime} \mathrm{W}\right)$ : situated in the northwest of the middle Atlas Mountain in Sefrou Province. Aichoune supports a semiarid climate with mean annual rainfall about $450 \mathrm{~mm}$. The mean altitude is $750 \mathrm{~m}$. It is an endemic focus of $L$. tropica.

2.1.5. Azrou Locality. $\left(31^{\circ} 30^{\prime} \mathrm{N}, 05^{\circ} 31^{\prime} \mathrm{W}\right)$ : situated in the south of the high Atlas Mountains in the province of Tinghir within the Saharan zone. The area has a Saharan climate with an altitude of about $1500 \mathrm{~m}$. The mean annual precipitation is less than $200 \mathrm{~mm}$. Tinghir is an emerging focus where the first human cases were declared in 2008.

2.2. Sand Flies Collection. Sand flies were collected bimonthly in animal shelters during their optimum development period in Morocco, between April and November 2011. Five collecting sites were randomly chosen in each village. In each trapping night, an average of 40 sticky traps were set for maximum $24 \mathrm{~h}$ in each sampling localities. All sand flies collected were identified morphologically to species level using morphological key [12]. Morphological differentiation between males of Ph. perniciosus and Ph. longicuspis was made according to description of Pesson et al. [13].

2.3. Data Analysis. In order to characterize the sand fly populations in different sites, three parameters were calculated:

(i) density of sand flies collected: number of specimens $/ \mathrm{m}^{2}$ of sticky traps;

(ii) relative frequency: number of specimens of species $(x) /$ total number of specimens $\times 100$;

(iii) species richness: number of species in a given area.

\section{Results}

3.1. Diversity, Distribution, and Abundance of Phlebotomine Species. During this study, a total of 3156 sand flies with 2627 males (83\%) and 529 females (17\%) were collected from the five study locations. Their identification revealed the presence of 11 species belonging to two genera: seven Phlebotomus spp. (95.2\%) and four Sergentomyia spp. (4.8\%). Among the Phlebotomus spp., Phlebotomus sergenti Parrot was the predominant species (58.7\%) followed by Phlebotomus perniciosus Newstead (13.5\%), Phlebotomus longicuspis Nitzulescu (12.9\%), Phlebotomus papatasi Scopoli (12.6\%), Phlebotomus ariasi Tonnoir (01.4\%), Phlebotomus alexandri Sinton (0.6\%), and Phlebotomus chabaudi Croset, Abonnenc \& Rioux (0.3\%). Sergentomyia minuta Adler \& Theodor $(62.5 \%)$ was the most prevalent species in the Sergentomyia genus which comprised 3 others species (Table 1 ).

Five species (Ph. sergenti, Ph. perniciosus, Ph. longicuspis, Ph. papatasi, and S. minuta) were found common to all environments but with a varied predominance according to each species. Ph. sergenti was the dominant species in semi arid (64.9\%), arid (51.9\%), and subhumid (60.4\%) regions, whereas $\mathrm{Ph}$. papatasi was the most prevalent species in saharan environment (45.7\%). Ph. perniciosus was the second most abundant species in fresh semiarid (27.3\%) and subhumid (18.7\%) areas compared with Ph. longicuspis, which had significantly higher percent composition in arid (25.2\%) and saharan areas (13.5\%). In low altitude of semiarid, $P h$. longicuspis and $\mathrm{Ph}$. perniciosus are in similar proportions with, respectively, $8.5 \%$ and $7.8 \%$. Ph. ariasi was present only at high altitudes $(>1000 \mathrm{~m})$ in three biotopes (subhumid, semiarid, and Saharan). Ph. alexandri and Ph. chabaudi were less prevalent and less widespread.

The greatest species richness was found in Ait Chribou, a semiarid area with fresh winter located at $1200 \mathrm{~m}$ altitude, with the occurrence of nine species against eight species occurring in Azrou, a Saharan biotope at $1500 \mathrm{~m}$ altitude.

3.2. Seasonal Occurrence of Sand Flies Species. The seasonal trends shown by each vector are illustrated in Figure 2.

Except in subhumid area where seasonal activity of sand flies extended from May to October (6 months) (Figure 2(c)), the activity period of the species starts from April and lasts to November ( 8 months) in the others biotopes (Figures 2(a), 2(b), 2(d), and 2(e)). At Aichoune, Ait Bousdouk, Ait Chribou, and Bouassem, the majority of sand flies, dominated by $P h$. sergenti, were collected between April and June. At Azrou locality, where $P h$. papatasi is predominating, the majority was collected between August and September.

$P h$. sergenti displayed a biphasic trend with a first and more important peak, situated between end of spring and beginning of summer, depending on sites. A second peak is observed in the beginning of autumn. Ph. longicuspis was more abundant in May and in August, respectively at Ait Bousdouk (Figure 2(b)) and Azrou (Figure 2(e)). Ph. perniciosus was more prevalent in September and October, respectively at Bouassem (Figure 2(c)) and Ait Chribou (Figure 2(a)). In saharan areas, activity of $P h$. papatasi begins at the end of April, lasting to November with two peaks, a first one in June and a more important one in August-September (Figure 2(e)).

\section{Discussion}

Among 23 species described in Morocco, eleven sand fly species (48\%) were identified in this study. The identified species belong to two genera: Phlebotomus, and Sergentomyia. Species in Phlebotomus genus belong to three different subgenera: Phlebotomus, Paraphlebotomus, and Larroussius.

In Larroussius subgenus, we reported three species: $P h$. longicuspis, Ph. Perniciosus, and Ph. ariasi. These three species are proven vectors of L. infantum [14]. In Paraphlebotomus subgenus, we also identified three species: $P h$. sergenti, $P h$. Alexandri, and Ph. chabaudi. The first one is the proven vector of L. tropica in Morocco [11]. Ph. papatasi was the sole species belonging to Phlebotomus subgenus in our collection. This species is the proven vector of L. major in Morocco [15]. The four species belonging to Sergentomyia genus (S. minuta, $S$. 


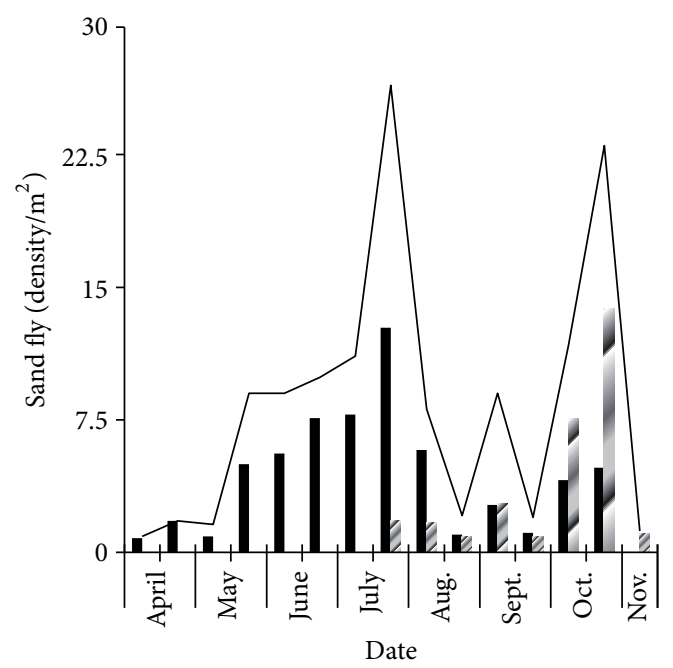

(a)

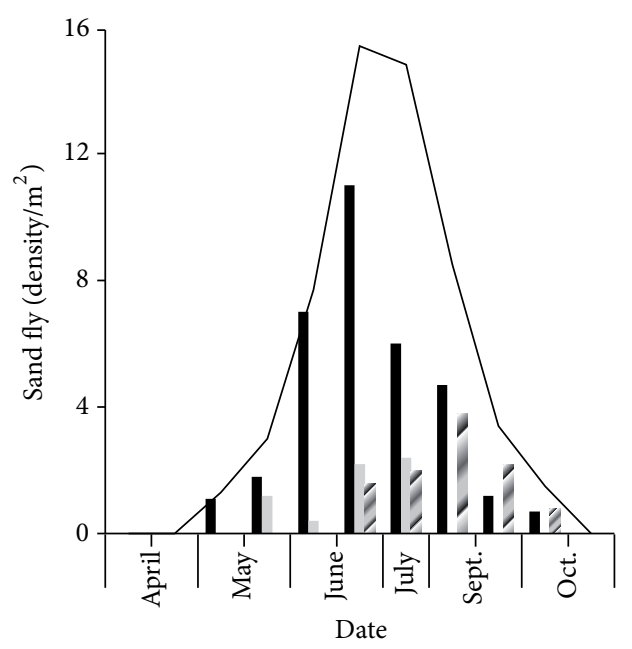

(c)

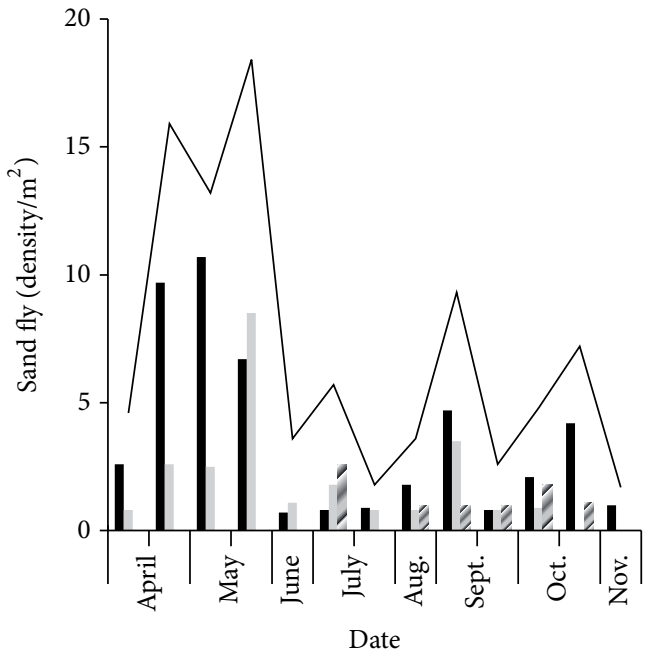

(b)

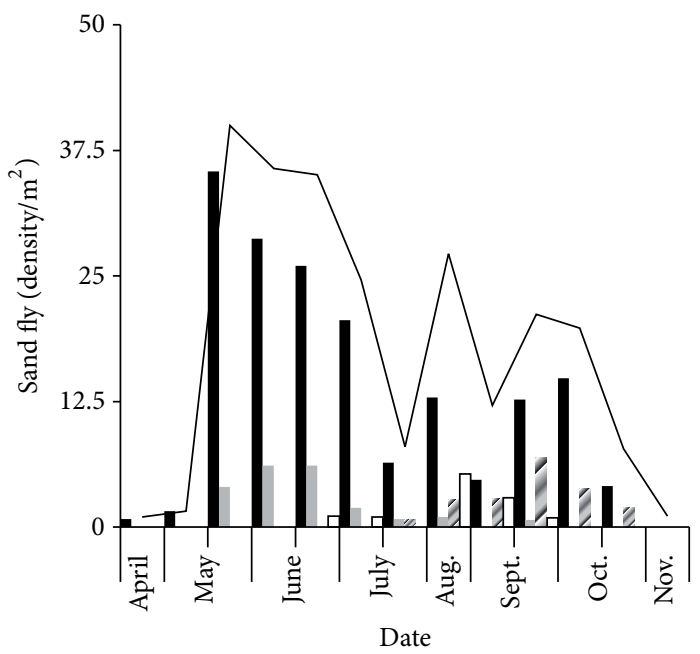

(d)

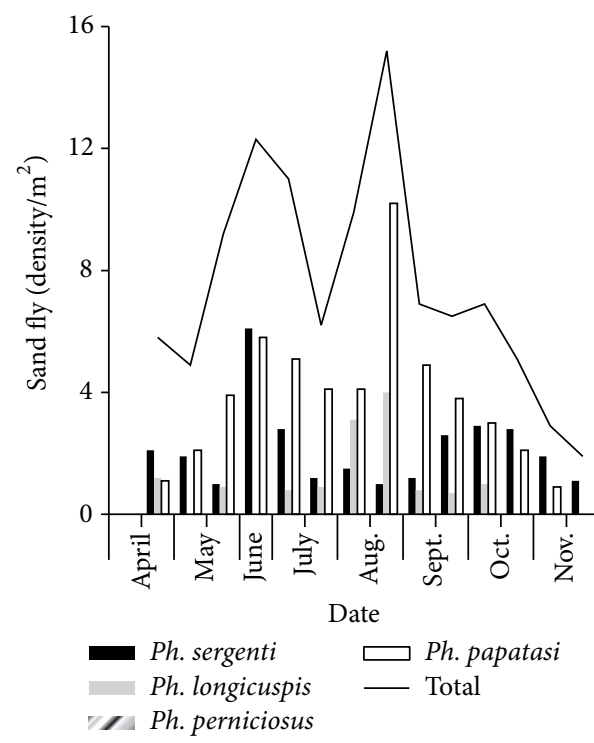

(e)

FIGURE 2: Seasonal variations of the most frequent sand fly species collected in each studied areas. (a) Ait Chribou locality, Azilal province, Semiarid area, 1200 m; (b) Ait Bousdouk locality, Essaouira province, arid area, 250 m; (c) Bouassem locality, Boulmane province, subhumid area, 1100 m; (d) Aichoune locality, Sefrou province, semiarid area, 750 m; (e) Azrou locality, Tinghir province, Saharan area, 1500 m. 


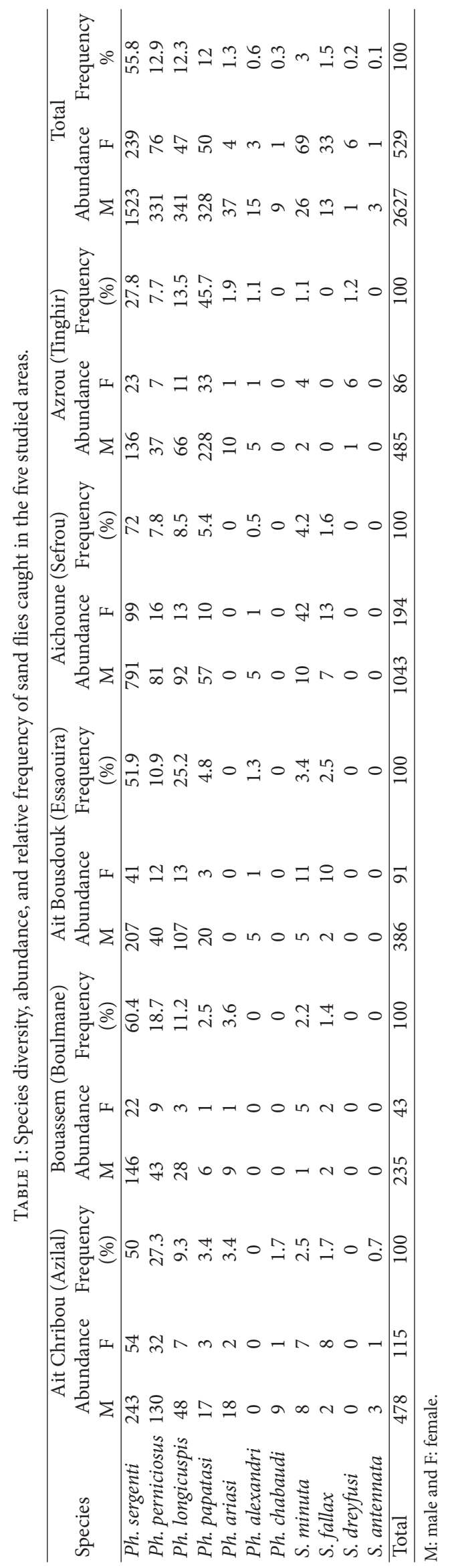


fallax, S. antennata, and S. dreyfusi) were weakly represented in sand fly fauna caught in this study. These species are known to be less abundant in human settings $[16,17]$.

The species richness was the highest in Ait Chribou locality (semiarid area at $1200 \mathrm{~m}$ asl). Nine out of eleven species collected from the study area are present in this locality. However, $77.3 \%$ of specimens collected were $P h$. sergenti and Ph. Perniciosus, and only $22.7 \%$ are belonging to the seven remaining species. Azrou locality (saharan area at $1500 \mathrm{~m}$ asl) also displayed a rich sand fly fauna with eight species. Previous studies in the High-Atlas Mountains have linked biodiversity to altitude $[18,19]$. The high species diversity has been found at about $800 \mathrm{~m}$ altitude. Boussaa et al. [19] highlighted, moreover, the importance of aspect in sand fly diversity. They noted that the east-facing sites were generally richer in sand fly species than the west-facing sites in Morocco. Similar data were found in southern Anatolia, Turkey [20] where the highest biodiversity was found at about $900 \mathrm{~m}$ asl. Our results do not meet completely with these findings, we have recorded a high diversity at $1500 \mathrm{~m}$ in Saharan area. Rioux et al. [4], by structuring species on bioclimate basis, have also noticed the high diversity in Saharan areas.

Of the five vectors we described, $P h$. sergenti, Ph. perniciosus, Ph. longicuspis, and Ph. papatasi have been the most common species found in this study. They were collected at all biotopes. Other studies also indicated that these species are the most common sand flies in Morocco $[2,18,19]$. These species are known to be dominant in anthropic environments and are easily collected inside and in the vicinity of human dwellings $[16,17]$.

$P h$. sergenti was the most frequently collected sand fly representing $55.8 \%$ of the specimens caught from various habitats. It was the most abundant species in arid (51.9\%), semiarid (64.9\%), and subhumid (60.4\%) areas. Its highest density (72\%) was registered at Aichoune locality, a semiarid area at $750 \mathrm{~m}$ asl. In Saharan areas, it represented the second most abundant species, after $\mathrm{Ph}$. papatasi. Adults of $\mathrm{Ph}$. sergenti were active throughout 8 months (April-November) in arid, semiarid, and Saharan areas and during 6 months (May-October) in subhumid areas showing a bimodal distribution. Previous studies showed that this species is largely widespread in Morocco without being the most abundant. It was proved to be more associated with arid and semiarid bioclimates $[4,21,22]$. Its activity period was investigated in Taza, a semi arid area in northern Morocco, where it was collected from June to November showing two density peaks [6]. The same activity period has been reported in Chichaoua province, a mountainous semi arid area in the southwest of High Atlas Mountains, but with only one density peak [4]. While, in $\mathrm{Al} \mathrm{Haouz} \mathrm{plain,} \mathrm{an} \mathrm{arid} \mathrm{area} \mathrm{in}$ southwestern Morocco, this species was active only during the period April-June and absent in the rest of the year [8]. Compared to these studies, our findings show an increase in $P h$. sergenti abundance, even in biotopes where the species was less prevalent (subhumid and Saharan areas) and an extension of its activity period. These results could explain the increase in ACL incidence in Morocco and its extension to new nonendemic regions (Boulmane and Tinghir). In fact,
15 years ago, Rioux et al. [22] have predicted, such expansion in subhumid areas using a model in which temperature parameters were varied to simulate global warming.

The emergence of ACL in Tinghir (Saharan area) could be linked to local changes. Indeed, this region has undergone a high level of environmental degradation over the last years. The human population has increased, especially in areas where housing conditions are unfavorable. The establishment of animal settlements in the vicinity of households and the population's movement from neighboring endemic areas has favored leishmaniasis transmission in this province.

After Ph. sergenti, Ph. perniciosus was the second most collected species in this study. Its highest density was noted at Ait Chribou at $1200 \mathrm{~m}$. This result is in line with previous reports in High Atlas mountains $[18,19]$. However, contrary to the results of Guernaoui et al. [18] who have suggested the absence of this species below $600 \mathrm{~m}$ asl, we have found it in the lowland at $250 \mathrm{~m}$. As noted by the last authors, the male of Ph. perniciosus was mainly found in atypical form in the five study sites. Its density was underestimated in earlier studies because, in this form, it was confused with its sympatric species Ph. longicuspis. Ph. longicuspis was strongly indicated as the most abundant Larroussius species, while $P h$. perniciosus was considered to be much less prevalent in Morocco $[2,21]$. Ph. perniciosus was more abundant in our collections from early summer and reached its maximum density in September-October. Guernaoui et al. [7] found similar results in Chichaoua province.

$P h$. longicuspis shows also a wide distribution including all bioclimatic zones and all altitudes. This species was most abundant in arid (Ait Bousdouk, $250 \mathrm{~m}$ ) and saharan (Azrou, $1500 \mathrm{~m}$ ) bioclimate which is consistent with previous distribution reports $[4,21]$. These results are in contradiction with those of Guernaoui et al. [18] who showed, in the same region of High Atlas Mountains, that Ph. longicuspis was more abundant between 600 and $799 \mathrm{~m}$ altitude, while its density became much lower outside this range. The altitude alone does not seem to be a selective factor for sand fly distribution in Morocco, characterized by a large climatic and ecologic diversity. Bioclimate, taking in account, many factors, mainly climatic factors, seems to better explain sand fly distribution in Morocco. Adults of Ph. longicuspis displayed a bimodal annual abundance pattern with peaks in May and September in arid areas. In saharan areas, it showed only one peak in August. According to Guernaoui et al. [7], this species showed a monophasic cycle in Chichaoua province, southwestern of Morocco, with one density peak in August-September. The large distribution and the occurrence with considerable density and long activity period of members of the subgenus Larroussius are a cause for concern and indicate the high potential risk of $L$. infantum transmission in the studied areas.

$P h$. papatasi, was found in all biotopes and at all altitudes but at relatively low number except in Azrou (saharan area, $1500 \mathrm{~m}$ ) where it was the most collected sand fly, representing $45.7 \%$ of the specimens. Ph. papatasi has been described as a sub-Saharan vector. It is the most commonly collected species in arid and per arid areas $[4,8,21]$.In a study conducted in 2002 in southwestern Morocco, Guernaoui et al. [18] reported negative association between altitude and 
Ph. papatasi abundance. They indicated that the species was predominant in plain (400-599 $\mathrm{m}$ ), rare at the other altitudes and absent from $1200 \mathrm{~m}$ asl. Boussaa et al. [19] indicated, in the same region, that $P h$. papatasi was most abundant at sites lying at 400-800 m asl. In southern Anatolia, Turkey, Simsek et al., [20] indicated that the species was more abundant at the range of 0-600 m altitude (76.8\%). Our results are clearly in conflict with these findings. As for the others species, $P h$. papatasi distribution seems to be determined mainly by bioclimate. In Azrou, where it is abundant, Ph. papatasi populations were prevalent from April to November with two peaks. These data are in accordance with earlier results from Marrakech area in southwestern Morocco [8].

The complexity of leishmaniasis in Morocco make their management challenging. Data obtained in this study which represented spatial and seasonal trends of the most important sand fly vectors confirm a serious concern. They might be helpful in prediction of areas and period of maximum risk for leishmaniasis transmission. Prevention and control should be an integrated approach including case treatment and application of appropriate reservoir and vectors control.

\section{Conflict of Interests}

The authors declare that they have no conflict of interests.

\section{Authors' Contribution}

C. Faraj conceived and designed the study and drafted the paper. E. Adlaoui carried out the data analysis and participated in the review of the paper. S. Ouahabi carried out sand flies identification and participated in the review of the paper, M. ElKhohli, L. Lakraa, M. ElRhazi carried out the field work and participated in the sand flies identification. B. Ameur has given financial support and participated in the review of the paper. All authors read and approved the final version of the paper.

\section{Acknowledgments}

This study received financial support from WHO Project ID no. EMDCD 1004953. The authors wish to thank the staff of medical Delegations of Azilal, Boulmane, Essaouira, Sefrou, and Tinghir for their kind assistance in the field work.

\section{References}

[1] S. Iguermia, T. Harmouche, O. Mikou, A. Amarti, and F. Z. Mernissi, "Mucocutaneous leishmaniasis in Morocco, evidence of the parasite's ecological evolution?" Medecine et Maladies Infectieuses, vol. 41, no. 1, pp. 47-48, 2011.

[2] J. A. Rioux, "Trente ans de coopération franco-marocaine sur les leishmanioses: dépistage et analyse des foyers. Facteurs de risque. Changements climatiques et dynamique nosogéographique," Association des Anciens ELèves de L'Institut Pasteur, vol. 168, pp. 90-101, 2001.

[3] M. Rhajaoui, "Les leishmanioses humaines au Maroc: une diversité nosogéographique," Pathologie Biologie, vol. 59, no. 4, pp. 226-229, 2011.
[4] J. A. Rioux, P. Rispail, G. Lanotte, and J. Lepart :, "Relations Phlébotomes-bioclimats en écologie des leishmanioses Corollaires épidémiologiques. L'Exemple Du Maroc," Actualités Botaniques, pp. 549-557, 1984.

[5] P. D. Ready, "Leishmaniasis emergence and climate change," OIE Revue Scientifique et Technique, vol. 27, no. 2, pp. 399-412, 2008.

[6] N. Guessous-Idrissi, S. Chiheb, A. Hamdani et al., "Cutaneous leishmaniasis: an emerging epidemic focus of Leishmania tropica in north Morocco," Transactions of the Royal Society of Tropical Medicine and Hygiene, vol. 91, no. 6, pp. 660-663, 1997.

[7] S. Guernaoui, A. Boumezzough, B. Pesson, and G. Pichon, "Entomological investigations in Chichaoua: an emerging epidemic focus of cutaneous leishmaniasis in Morocco," Journal of Medical Entomology, vol. 42, no. 4, pp. 697-701, 2005.

[8] S. Boussaa, S. Guernaoui, B. Pesson, and A. Boumezzough, "Seasonal fluctuations of phlebotomine sand fly populations (Diptera: Psychodidae) in the urban area of Marrakech, Morocco," Acta Tropica, vol. 95, no. 2, pp. 86-91, 2005.

[9] C. Sauvage, "Etages bioclimatiques au Maroc," in Atlas du Maroc, vol. 1, p. 44p, Inst SC Chérif, Rabat, Morocco, 1963.

[10] P. Marty, Y. Le Fichoux, F. Pratlong, J. A. Rioux, G. Rostain, and J. P. Lacour, "Cutaneous leishmaniasis due to Leishmania tropica in a young Moroccan child observed in Nice, France," Transactions of the Royal Society of Tropical Medicine and Hygiene, vol. 83, no. 4, article 510, 1989.

[11] E. Guilvard, J. A. Rioux, M. Gallego et al., "Leishmania tropica in Morocco. III-The vector of Phlebotomus sergenti. Apropos of 89 isolates," Annales de Parasitologie Humaine et Comparee, vol. 66, no. 3, pp. 96-99, 1991.

[12] Moroccan Ministry of Health, Lutte Contre les Leishmanioses, Guide des Activités, 2010.

[13] B. Pesson, J. S. Ready, I. Benabdennbi et al., "Sandflies of the Phlebotomus perniciosus complex: mitochondrial introgression and a new sibling species of P. longicuspis in the Moroccan Rif," Medical and Veterinary Entomology, vol. 18, no. 1, pp. 25-37, 2004.

[14] J. A. Rioux, G. Lanotte, F. Petter et al., "Les leishmanioses cutanées du bassin Méditerranéen occidental, de lidentification enzymatique à l'analyse éco-épidémiologique. L'exemple de trois "foyers", tunisien, marocain et français," in Leishmania. Taxonomie et Phylogenèse. Applications Eco-Epidémiologiques, pp. 2365-6395, Colloque International CNRS/INSERM/OMS, Institut Méditerranéen d'Etudes Epidemiologiques et Ecologiques, Montpellier, France, 1986.

[15] J. A. Rioux, E. Guilvard, J. Dereure et al., "Infestation naturelle de Phlebotomus papatasi (Scopoli, 1786) par Leishmania major MON-25. A propos de 28 souches isolées dans un foyer du Sud Marocain," in Leishmania. Taxonomie et Phylogenèse. Applications Eco-Epidémiologiques, pp. 2471-6480, Colloque International CNRS/INSERM/OMS, Institut Méditerranéen d'Etudes Epidemiologiques et Ecologiques, Montpellier, France, 1986.

[16] K. Ramaoui, S. Guernaoui, and A. Boumezzough, "Entomological and epidemiological study of a new focus of cutaneous leishmaniasis in Morocco," Parasitology Research, vol. 103, no. 4, pp. 859-863, 2008.

[17] S. Boussaa, B. Pesson, and A. Boumezzough, "Faunistic study of the sandflies (diptera: Psychodidae) in an emerging focus of cutaneous leishmaniasis in Al Haouz province, Morocco," Annals of Tropical Medicine and Parasitology, vol. 103, no. 1, pp. 73-83, 2009. 
[18] S. Guernaoui, A. Boumezzough, and A. Laamrani, "Altitudinal structuring of sand flies (Diptera: Psychodidae) in the HighAtlas mountains (Morocco) and its relation to the risk of leishmaniasis transmission," Acta Tropica, vol. 97, no. 3, pp. 346-351, 2006.

[19] S. Boussaa, M. Neffa, B. Pesson, and A. Boumezzough, "Phlebotomine sandflies (Diptera: Psychodidae) of southern Morocco: results of entomological surveys along the Marrakech-Ouarzazat and Marrakech-Azilal roads," Annals of Tropical Medicine and Parasitology, vol. 104, no. 2, pp. 163-170, 2010.

[20] F. M. Simsek, B. Alten, S. S. Caglar et al., "Distribution and altitudinal structuring of phlebotomine sand flies (Diptera: Psychodidae) in southern Anatolia, Turkey: their relation to human cutaneous leishmaniasis," Journal of Vector Ecology, vol. 32, no. 2, pp. 269-279, 2007.

[21] H. Bailly-Choumara, E. Abonnenc, and J. Pastre :, "Contribution à l'étude des phlébotomes du Maroc. (Diptera : Psychodidae): données faunistiques et écologiques," Cahiers ORSTOM. Série Entomologie Médicale et Parasitologie, vol. 9, no. 4, pp. 431-460, 1971.

[22] J. A. Rioux, O. Akalay, J. Périères et al., "Lévaluation écoépidémiologisque du "risque leishmanien" au Sahara atlantique marocain. Intérêt heuristique de la relation 'phlébotomesbioclimats"' Ecologia Mediterranea, vol. 23, pp. 73-92, 1997. 


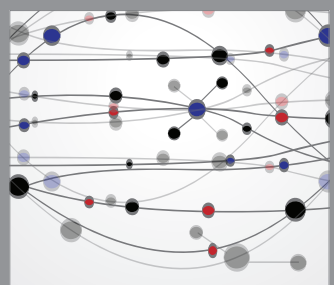

The Scientific World Journal
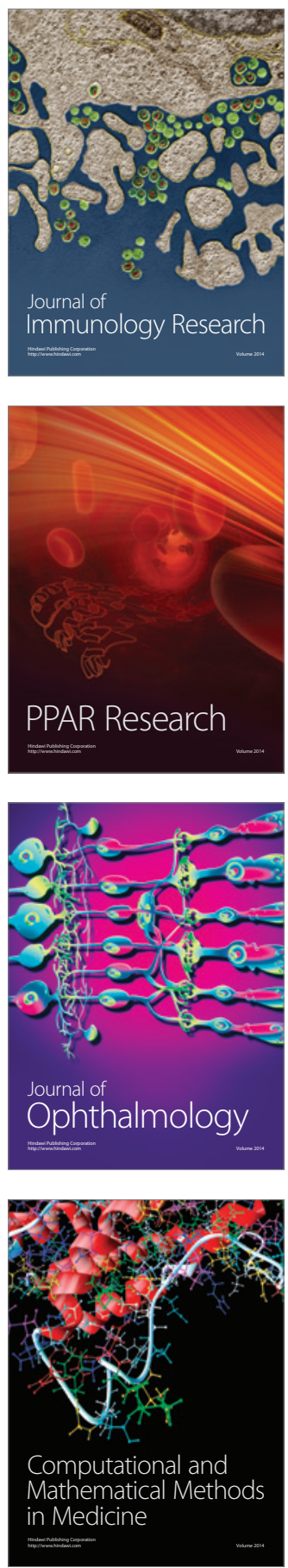

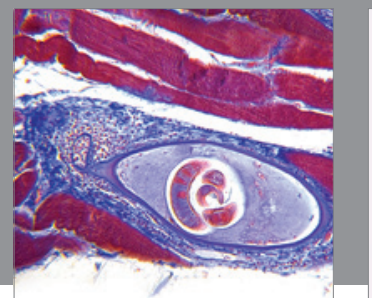

Gastroenterology

Research and Practice
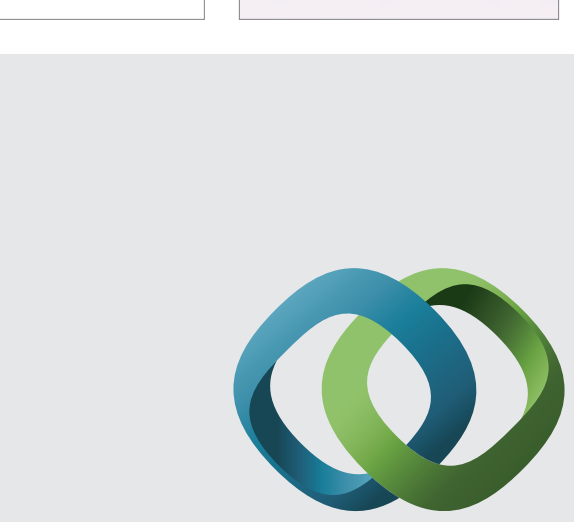

\section{Hindawi}

Submit your manuscripts at

http://www.hindawi.com
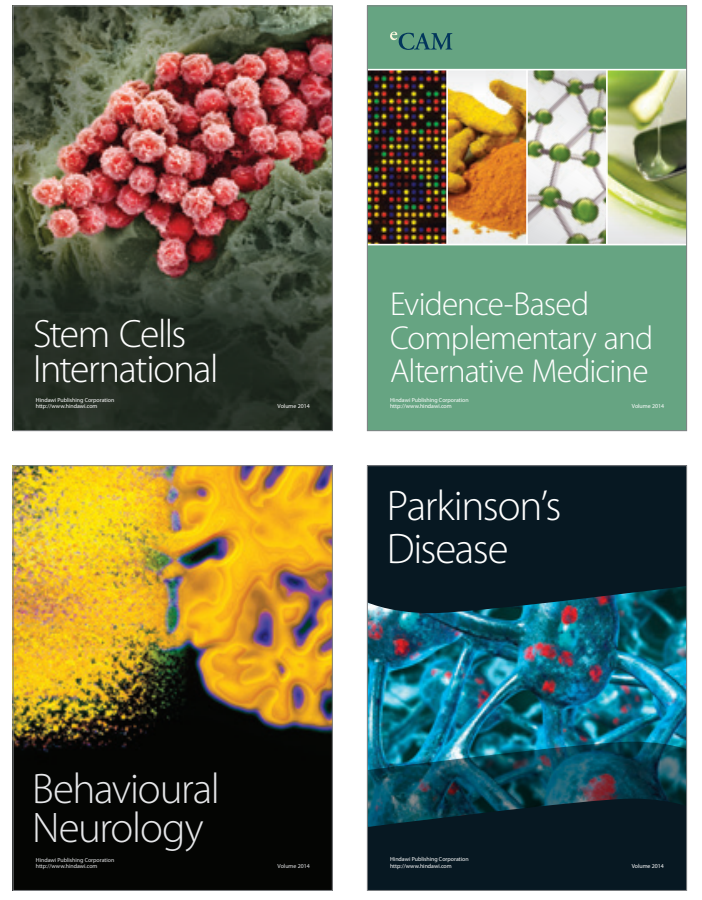
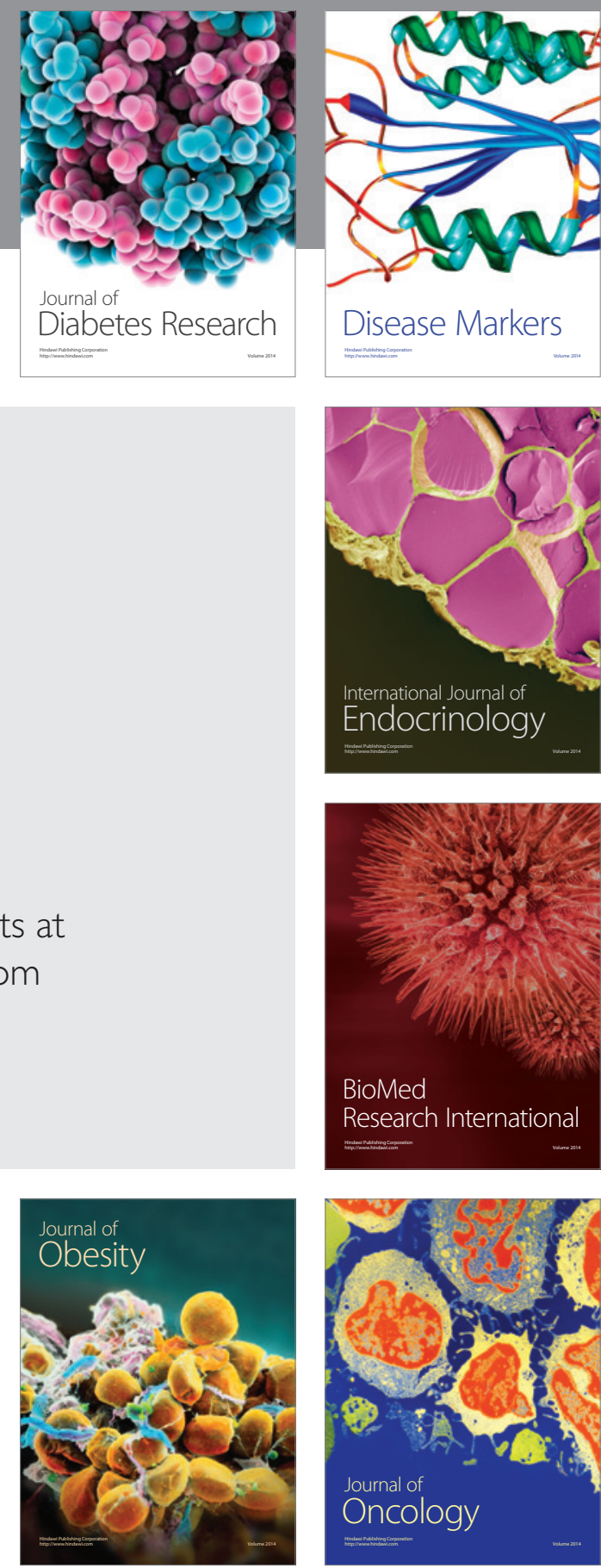

Disease Markers
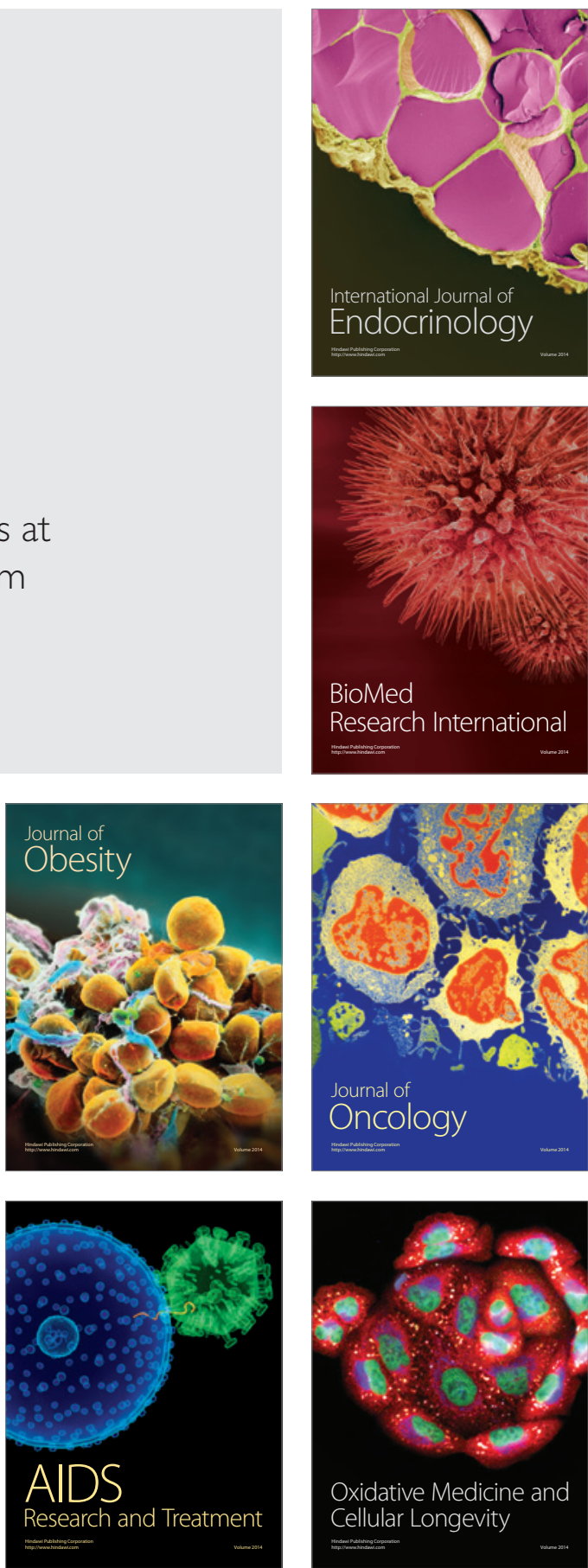